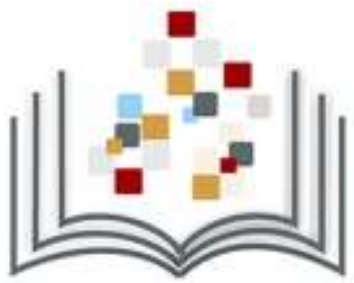

\title{
CAPACITAÇÃO DE EDITORES E EQUIPE EDITORIAL NA UFMG
}

Sérgio Dias Cirino ${ }^{1 *}$, Carla Cristina Vieira de Oliveira ${ }^{1}$, Leandro Castella César ${ }^{1}$, Bruno Oliveira $^{1}$, Lindiwe Fideles ${ }^{1}$, Marcella Boehler ${ }^{1}$, Priscila Nardy ${ }^{1}$, Vanessa Pastorini ${ }^{1}$

1 Universidade Federal de Minas Gerais - Pró-Reitoria de Pesquisa - Belo Horizonte (MG) - Brasil

*Autor correspondente: bolsistasprpq@gmail.com

\section{Como citar:}

Cirino, Sérgio D. et al.. Capacitação de editores e equipe editorial na UFMG. In: WORKSHOP DE EDITORAÇÃO CIENTíFICA, 9., 2016, São Paulo. Anais... São Paulo: Associação

Brasileira de Editores Científicos, 2016. p. 49-53

DOI: http://dx.doi.org/10.21452/wec.IXwec.2016.0010

\section{RESUMO}

O 1ํㅡㄹ Ciclo de formação de Editores é uma ação prevista na Política de Periódicos da Universidade Federal de Minas Gerais (UFMG). Implantada em outubro de 2015, a Política é um compromisso da gestão da atual reitoria da Universidade. Até 2015, a instituição não tinha ciência da quantidade exata de periódicos científicos que possuía, embora algumas tentativas anteriores tenham ocorrido com este propósito. A Política de Periódicos da UFMG proporcionou à comunidade acadêmica a visibilidade das publicações, bem como o apoio a melhoria conjunta dos periódicos através de ações como: avaliação sistemática dos periódicos, formação dos editores e do seu corpo técnico, incentivo à internacionalização, orientação e acompanhamento à submissão das revistas aos indexadores e implantação de um portal de periódicos. Esse trabalho é um estudo de caso do Portal de Periódicos da UFMG, que apresenta o resultado da implementação da ação de formação continuada dos editores e corpo técnico através de uma série de palestras que compuseram o $1^{\circ}$ Ciclo de formação de Editores da UFMG.

\section{INTRODUÇÃO}

Os periódicos científicos são essenciais para a comunicação científica, porém, nos estudos de qualidade de periódicos, as maiores críticas encontradas na literatura referem-se à irregularidade das publicações, à ausência de normalização das publicações e dos artigos, à ausência de um corpo editorial idôneo, ao idioma da publicação, à falta de originalidade dos artigos e à escassez dos recursos financeiros (KRZYZANOWSKI e FERREIRA, 1998). Colaborou, até certo ponto, para a superação de parte desses problemas o surgimento das Tecnologias da Informação e Comunicação (TICs) e dos portais das universidades. Contudo, também trouxeram novos desafios. Isso porque, diante da complexidade da produção científica, as publicações encontram-se espalhadas no universo acadêmico e em alguns casos eram desconhecidas dentro de sua própria unidade, como relatam Garrido e Schwarz (2010, p. 59):

A organização de vários periódicos em portais levanta novas questões, uma vez que até pouco tempo nas Instituições de Ensino Superior, os periódicos impressos e muitos digitais eram considerados apenas 
individualmente. A questão que se coloca no estudo é como as instituições organizam e estruturam esse novo serviço, uma coletânea de periódicos científicos de várias áreas do conhecimento, pertencentes à mesma instituição, até então dispersa em periódicos científicos impressos e iniciativas isoladas.

Anteriormente, ao caso aqui analisado, houve iniciativas com o intuito de conhecer os periódicos científicos da UFMG, tais como um estudo realizado por professores da Escola de Ciência da Informação (ECI) na década de 1990, que contabilizou 27 periódicos, e um levantamento realizado em 2006 pela Biblioteca Universitária cujo resultado encontrou 42 publicações. Entretanto, é a partir de 2014 que um levantamento dos periódicos publicados no âmbito da UFMG se firmará como primeiro passo de uma Política de Periódicos da instituição. Tendo sido encontrados 88 periódicos, o segundo passo foi estabelecer critérios de inclusão inicial dos periódicos no Portal, lançado juntamente com a Política em 22 de outubro de 2015. Cinco critérios foram estipulados: 1) Pertença: o periódico deveria ser editado por membro da UFMG (Docente, Discente ou Técnico); 2) Caracterização: o periódico precisa ter International Standard Serial Number (ISSN) impresso e/ou eletrônico; 3) Disponibilização: o periódico precisa ter acesso aberto e Uniform Resource Locator (URL) ativa; 4) Qualidade: o periódico precisa ter um comitê editorial; e 5) Atualidade: o periódico deveria ter publicado pelo menos em $2013^{1}$.

Além dos critérios, a Política foi pautada por dois princípios: 1) inclusão, garantindo portanto, a diversidade das áreas; e 2) excelência, buscando atender os critérios de qualidade nacional e internacional. Atendendo critérios e princípios, 62 periódicos foram selecionados. Tais publicações integram o Portal de Periódicos da UFMG, os quais divulgam a produção científica da universidade com impacto no grau de visibilidade externa dos periódicos da instituição. Rodrigues e Fachin (2008) lembram que a criação de um portal requer algumas atividades integradas como estrutura organizacional, recursos financeiros associados e responsabilidade institucional. Na UFMG os editores são professores da instituição que, além de não possuírem uma formação específica, muitas vezes são convidados ou se dispõem a exercerem esta função sem nenhum treinamento, equipe ou estrutura física. Considerando esse aspecto, uma das ações da Política de Periódicos foi a organização de um ciclo de palestras de formação das Equipes Editoriais, tendo por objetivos principais: possibilitar a capacitação em temáticas direcionadas à editoração e à normalização, além de fornecer subsídios para que editores e equipe possam fazer com que seus periódicos atendam critérios de qualidade nacionais e internacionais. $O$ próximo tópico aborda este ciclo.

A organização dos portais retrata um modelo alternativo de comunicação científica, assim como os repositórios digitais e as bibliotecas digitais, os quais possibilitam a disseminação e o desenvolvimento da produção científica (RODRIGUES; FACHIN, 2010). Normalmente, o professor recebe a editoração como uma atividade a mais nos seus encargos diários, uma vez que a formação dos editores é fundamentada pela prática, o que, em média, acontece em oito anos (MUNTERS,1981). O dia a dia no trabalho com os editores revela a necessidade de oferecer à equipe de editoração um apoio ao uso das normas que orientam a publicação de periódicos e artigos científicos, muitos apresentavam editoração amadora, além de contribuir para padronização com o objetivo de aumentar a visibilidade e o reconhecimento das publicações (GRANTS; BEM e ALVES, 2012). Com o objetivo de minimizar as diferenças estruturais e capacitar os editores e a equipe editorial dos periódicos científicos pertencentes ao Portal de Periódicos da UFMG, desenvolveu-se, no primeiro semestre de 2016, o 1ํㅡㄹ Ciclo de Formação de Editores.

1 Visando permitir a entrada de maior quantidade de periódicos, este critério acabou sendo afrouxado de modo que publicações que não o atendiam foram incluídas. 
Desde a década de 1990, a literatura especializada aponta que uma grande dificuldade dos editores diz respeito à falta de cultura acadêmica de publicação com condições institucionais para a sobrevivência dos periódicos (MIRANDA e PEREIRA, 1996). Um programa de capacitação que desenvolva através da implementação de seminários uma forma de ampliar e desenvolver competências necessárias para a editoração de periódicos é fundamental para adoção de um padrão de qualidade que possibilite maior visibilidade, padronização e credibilidade das publicações da universidade. Nesse sentido, para que o pilar da excelência da Política de Periódicos se cumpra são fundamentais ações de capacitação integral da equipe editorial que fomentem e respaldam a melhoria da equipe e, consequentemente, dos periódicos, como o $1^{\circ}$ Ciclo de Formação de Editores.

\section{METODOLOGIA}

Em análise dos primeiros atendimentos realizados pela Incubadora de Periódicos da UFMG ${ }^{2}$ e considerando as dúvidas mais recorrentes apresentadas pelas Equipes Editoriais destes, procurou-se abordar as seguintes temáticas no 10 ciclo de editores, para as quais foram convidados especialistas, conforme descrito abaixo:

- Critérios de entrada e permanência no SciELO - Abel Packer;

- Critérios para indexação em bases de dados - Carla Oliveira e Fernanda Almeida;

- Processo editorial de periódicos: revisão e normalização - Leila Anastácio e Lourdes Nascimento;

- Sistema Eletrônico de Editoração de Revistas (SEER) - Teresinha de Souza e Cássia Gonzalez;

- Bases de citações e bibliometria: aumentando a visibilidade dos periódicos Max Mattos;

- Fator de impacto: desafios contemporâneos (Maria Clarice Batista e Sérgio Cirino).

Após o aceite dos instrutores e confirmação da temática e dos títulos, iniciou-se o processo de agendamento dos locais sugeridos para apresentação. Para cada evento realizou-se a reserva de dois locais, um com capacidade menor e outro com capacidade ampliada. O local era confirmado somente após o fim do período de inscrições, o qual se iniciava um mês antes do evento propriamente dito. Para a realização das inscrições, foram elaborados dois tipos de formulários: um online que ficava disponível enquanto houvesse vagas e outro impresso de inscrição presencial no dia do evento. Ambos os formulários continham informações como nome, e-mail e telefone de contato, instituição de origem, além de breves perguntas sobre a participação em corpo editorial de algum periódico e sobre a participação nos eventos anteriores.

Verificavam-se, então, com os instrutores quais os recursos materiais necessários para sua atividade (itens de escritório, impressos, etc.); recursos tecnológicos (computador, data show, laboratório para prática etc.) e, se fosse o caso, serviços de hospedagem, transporte, alimentação, cobertura fotográfica, cerimonial, entre outros. A divulgação foi realizada em parceria com o setor de comunicação da UFMG (CEDECOM) e foram produzidas peças gráficas eletrônicas e impressas (em menor quantidade), banner, marcadores de páginas, além de ser noticiado no próprio Portal de Periódicos da UFMG, nas redes sociais a ele vinculadas, no site da UFMG e de outras unidades tidas como público-alvo, em sites externos de instituições como Sociedade Brasileira para o Progresso da Ciência (SBPC), Associação Brasileira de Editores Científicos (ABEC), etc.

Foi produzido, também, um check list padrão para certificar-se de que todos os itens foram verificados, se não foi deixado para trás nenhum aspecto, e também foi

${ }^{2}$ A Incubadora de Periódicos também integra a Política de Periódicos, com ações auxiliadoras aos periódicos da UFMG. 
elaborado um cronograma de atividades a ser distribuído ao comitê executivo e/ou outros membros que possam somar a execução do evento. Toda a logística foi estabelecida através de reuniões periódicas de planejamento e algumas medidas não previstas (sinalização, questões adicionais no formulário de inscrição etc.) foram tomadas de acordo com as experiências das palestras anteriores fazendo com que os procedimentos fossem se aperfeiçoando a cada palestra.

\section{RESULTADOS E DISCUSSÃO}

A partir das planilhas geradas pelo formulário de inscrição online, das assinaturas colhidas no credenciamento nos dias do evento e do formulário de avaliação do Ciclo foi possível observar que, considerando todo o evento, foram 1059 inscritos dos quais 637 estiveram presentes nos eventos. Importante ressaltar que há representatividade de todas as áreas do conhecimento e de pessoas vinculadas não só a UFMG, mas de outras instituições nacionalmente distribuídas, sejam elas públicas ou privadas.

Foi possível observar também um perfil bastante diversificado dos interessados que se apresentaram como estudantes de graduação, estudantes de pós-graduação, técnico-administrativos, professores e outros profissionais ligados à área de editoração científica. Outra característica foi a de que aproximadamente $50 \%$ dos presentes fazem ou fizeram parte de corpo editorial, sendo que, dos 62 periódicos abrangidos pela Política de Periódicos da UFMG, 42 tiveram representantes nos eventos. Alguns desses dados coletados estão representados nas tabelas abaixo:

Tabela 1: Números de Inscritos e Presentes por Evento.

\begin{tabular}{|c|c|c|}
\hline Palestra & $\begin{array}{c}\text { № de } \\
\text { inscritos }\end{array}$ & № de Presentes \\
\hline $\begin{array}{c}\text { Critérios de entrada e permanência no } \\
\text { Scielo }\end{array}$ & 296 & 179 \\
\hline $\begin{array}{c}\text { Critérios para indexação em bases de } \\
\text { dados }\end{array}$ & 197 & 135 \\
\hline $\begin{array}{c}\text { Processo editorial de periódicos: revisão e } \\
\text { normalização }\end{array}$ & 226 & $52^{*}$ \\
\hline $\begin{array}{c}\text { Sistema Eletrônico de Editoração de } \\
\text { Revistas (SEER) }\end{array}$ & 83 & 95 \\
\hline $\begin{array}{c}\text { Bases de citações e bibliometria: } \\
\text { aumentando a visibilidade dos periódicos }\end{array}$ & 150 & 68 \\
\hline $\begin{array}{c}\text { Fator de impacto: desafios } \\
\text { contemporâneos }\end{array}$ & 107 & 637 \\
\hline Total & 1059 & 108 \\
\hline
\end{tabular}

*Este evento foi realizado em um laboratório com capacidade para 50 pessoas.

Tabela 2: Número de Presentes de Acordo com o Perfil.

\begin{tabular}{|c|c|}
\hline Perfil & № de Presentes \\
\hline Alunos de Graduação & 102 \\
\hline Alunos de Pós-Graduação & 108 \\
\hline Docentes & 159 \\
\hline Técnico-Administrativos & 186 \\
\hline Outros & 82 \\
\hline Total & 637 \\
\hline
\end{tabular}

\section{CONCLUSÕES}

A partir dos dados apresentados é possível evidenciar a relevância das ações da Política de Periódicos em promover a capacitação dos editores buscando a excelência desses profissionais e dos periódicos em si. Essas ações, que envolvem principalmente os atendimentos na Incubadora de Periódicos e $01^{0}$ Ciclo de Formação de Editores, demonstram o comprometimento da instituição em acompanhar a produção científica da comunidade acadêmica e do interesse dessa 
comunidade em buscar qualificação de pessoal e suporte de demandas específicas de cada periódico. Além disso, os resultados apontaram uma carência de cursos e/ou iniciativas ligadas à qualificação de editores e suas equipes uma vez que, os números inscritos e participantes apontam que há uma quantidade considerável de profissionais da UFMG e de outras instituições, públicas e privadas, que participaram ou participam de corpo editorial buscando essa qualificação.

\section{REFERÊNCIAS}

GARRIDO, Isadora dos S.; RODRIGUES, Rosangela S.; CATARINA, Santa. Portais de periódicos científicos online: organização institucional das publicações.

Perspectivas em Ciência da Informação, v. 15, n. 2, p. 56-72, 2010. Disponível em: $<$ http://portaldeperiodicos.eci.ufmg.br/index.php/pci/article/view/943/732>. Acesso em: 11 out. 2016

GRANTS, Andréa F. L.; BEM, Roberta M. de; ALVES, Maria B. M.. Competência informacional do editor de periódicos científicos e o papel educacional da biblioteca e do bibliotecário na disponibilização de conteúdos com qualidade: o portal de periódicos da UFSC. In: SEMINÁRIO NACIONAL DE BIBLIOTECAS UNIVERSITÁRIAS, 17. 2012, Gramado. Anais... Porto Alegre: UFRGS, 2012. Disponivel em: <http://www.snbu2012.com.br/anais/pdf/4QT4.pdf > Acesso em: 14 out. 2016.

KRZYZANOWSKI, Rosaly F.; FERREIRA, Maria C. G.. Avaliação de periódicos científicos e técnicos brasileiros. Ciência da informação, v. 27, n. 2, p. 165-175, 1998. Disponível em:

$<$ http://www.ufrgs.br/propesq1/sobrelinks/arquivos/Aval Per Cien Tec.pdf $>$. Acesso em: 13 out. 2016.

MIRANDA, Dely B. de; PEREIRA, Maria de N. F.. O periódico científico como veículo de comunicação: uma revisão de literatura. Ciência da informação, v. 25, n. 3, p. 375-382, 1996. Disponível em: < http://www.brapci.ufpr.br/brapci/index.php/article/download/8770 >. Acesso em 11 out. 2016.

MUNTERS, Quirinus J.. The social science editor as a gatekeeper. Journal of Research Communication Studies, 1981.

RODRIGUES, Rosângela S. ; FACHIN, Gleisy R. B.. Portal de periódicos científicos: um trabalho multidisciplinar. Transinformação, Campinas, v.22, n.1, p. 33-45, jan./abr.,2010. Disponível em: <http://periodicos.puccampinas.edu.br/seer/index.php/transinfo/article/view/483>. Acesso em 14 out. 2016.

PALAVRAS-ChAVE: Periódicos científicos. Portal de periódicos UFMG. 1 Ciclo de Formação de Editores. 